\title{
Methods for isolation and quantification of microfossil fish teeth and elasmobranch dermal denticles (ichthyoliths) from marine sediments
}

\author{
Elizabeth C. Sibert, Katie L. Cramer, Philip A. Hastings, and Richard D. Norris
}

\begin{abstract}
Ichthyoliths-microfossil fish teeth and shark dermal scales (denticles)-are found in nearly all marine sediments. Their small size and relative rarity compared to other microfossil groups means that they have been largely ignored by the paleontology and paleoceanography communities, except as carriers of certain isotopic systems. Yet, when properly concentrated, ichthyoliths are sufficiently abundant to reveal patterns of fish abundance and diversity at unprecedented temporal and spatial resolution, in contrast to the typical millions of years-long gaps in the vertebrate body fossil record. In addition, ichthyoliths are highly resistant to dissolution, making it possible to reconstruct whole fish communities over highly precise and virtually continuous timescales. Here we present methods to isolate and utilize ichthyoliths preserved in the sedimentary record to track fish community structure and ecosystem productivity through geological and historical time periods. These include techniques for isolation and concentration of these microfossils from a wide range of sediments, including deep-sea and coral reef carbonates, clays, shales, and silicate-rich sediments. We also present a novel protocol for ichthyolith staining using Alizarin Red $S$ to easily visualize and distinguish small teeth from debris in the sample. Finally, we discuss several metrics for quantification of ichthyolith community structure and abundance, and their applications to reconstruction of ancient marine food webs and environments.
\end{abstract}

Elizabeth C. Sibert. Society of Fellows, Harvard University, 78 Mount Auburn Street, Cambridge, Massachusetts 02138, USA; Scripps Institution of Oceanography, University of California, San Diego, 9500 Gilman Drive MC 0208, La Jolla, California 92093, USA. esibert@fas.harvard.edu

Katie L. Cramer. Scripps Institution of Oceanography, University of California, San Diego, 9500 Gilman Drive MC 0208, La Jolla, California 92093, USA. kcramer@ucsd.edu

Philip A. Hastings. Scripps Institution of Oceanography, University of California, San Diego, 9500 Gilman Drive MC 0208, La Jolla, California 92093, USA. phastings@ucsd.edu

Richard D. Norris. Scripps Institution of Oceanography, University of California, San Diego, 9500 Gilman Drive MC 0244, La Jolla, California 92093, USA. rnorris@ucsd.edu

Keywords: fish teeth; denticles; ichthyoliths; coral reefs; historical ecology; micropaleontology

Submission: 4 May 2016 Acceptance: 13 March 2017

Sibert, Elizabeth C., Cramer, Katie L., Hastings, Philip A., and Norris, Richard D. 2017. Methods for isolation and quantification of microfossil fish teeth and elasmobranch dermal denticles (ichthyoliths) from marine sediments. Palaeontologia Electronica 20.1.2T: $1-14$

palaeo-electronica.org/content/2017/1800-quantifying-ichthyoliths 


\section{INTRODUCTION}

Despite being relatively common in marine sediments, ichthyoliths, the isolated microfossil teeth, dermal denticles, and bone fragments of sharks and bony fishes (Figure 1), have been overlooked by much of the scientific community, overshadowed by more abundant and better studied foraminifera, nannofossils, and other microfossils, for research into biological responses to ancient climate and environmental change (Cifelli, 1969; Frerichs, 1971; Smit, 1982; Hallock and Schlager, 1986; Kelly et al., 1998; Hull et al., 2011). While understanding the response of these unicellular organisms to climate and biotic events provides insight into the sensitivity of marine ecosystems to global change, unicellular algae and protists are only the base of a complex marine ecosystem, which support a diverse array of consumers, including marine vertebrates.

Fishes are one of the most diverse and ecologically successful vertebrate clades (Nelson, 2006; Friedman and Sallan, 2012; Near et al., 2013) and are a hallmark of nearly all marine ecosystems. The presence and abundance of fish biomass is an indicator of how efficiently an ecosystem is functioning, in terms of transferring energy from the base of the food web to the upper tiers (Sprules and Munawar, 1986; Iverson, 1990), and therefore the abundance and composition of ichthyoliths may be a reasonable proxy for ecosystem structure and function. Moreover, there are typically excellent chronologies and relatively continuous sedimentation rates in many deep-sea sedimentary sequences (e.g., Hilgen, 1991; Westerhold et al., 2008; Hilgen et al., 2010). Thus, it is possible to capture unusually detailed histories of vertebrates, as compared to the typical temporal and spatial fragmentation of the terrestrially exposed body-fossil record. In recent, shallow marine sediments, ichthyoliths can reveal changes in both diversity and abundance of fishes and sharks in coastal systems - making it possible to reconstruct fish community responses to overfishing, reef environmental decline and anthropogenic climate change (Jackson et al., 2001).

While Paleozoic ichthyoliths have a rich history of study (Maisey, 1984; Turner, 2004), younger ichthyoliths (Late Mesozoic and Cenozoic) have largely been ignored by the paleontology community, excepting large shark teeth (Cappetta and Schultze, 2012), as the majority of stem diversity for living clades was established by the Mesozoic. Cretaceous and Cenozoic ichthyoliths have been used as carriers of several isotopic proxies, including neodymium as a water-mass tracer (Martin and Haley, 2000; Scher and Martin, 2004), and strontium, which can be used both as a weathering

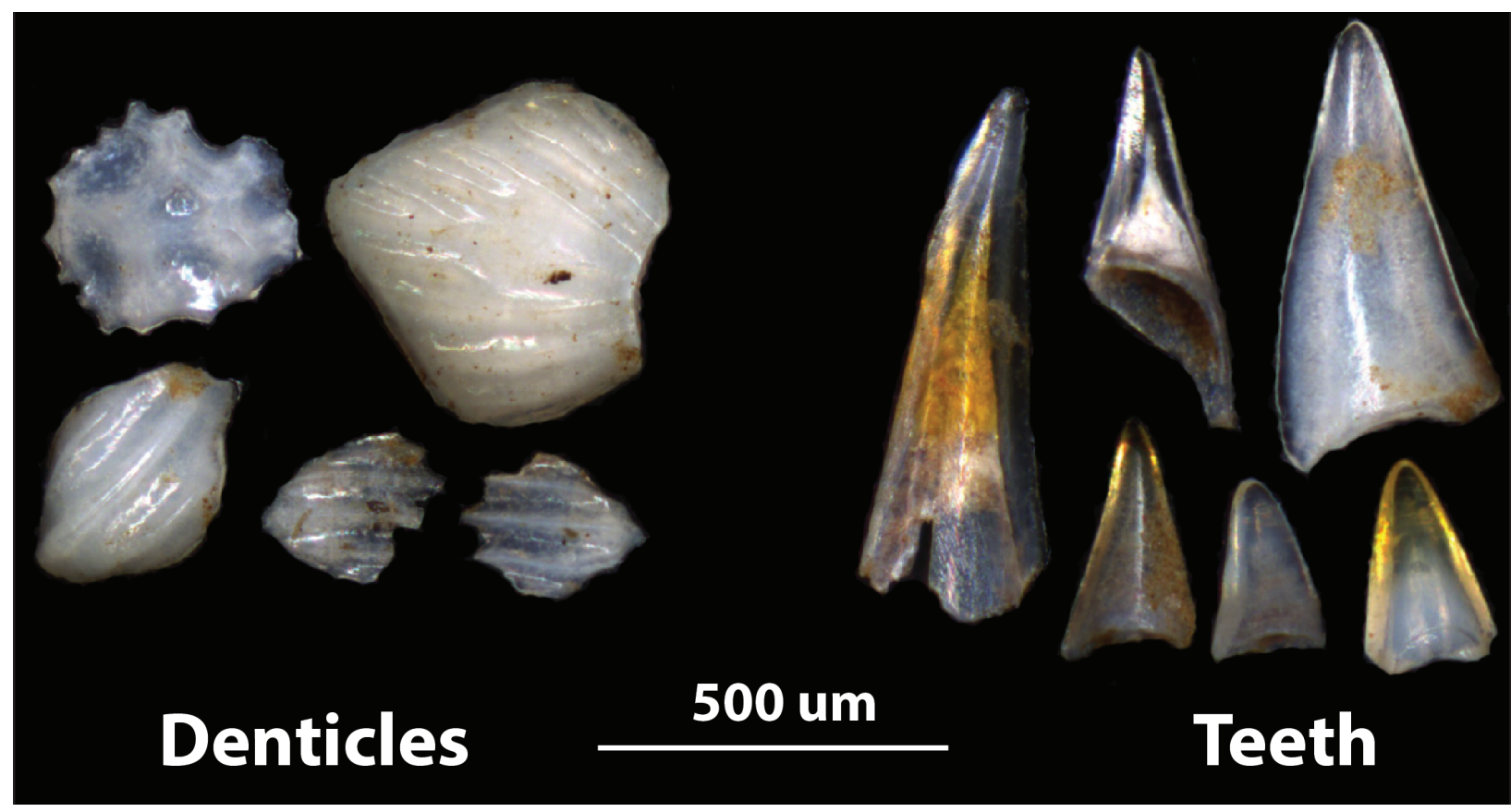

FIGURE 1. An assortment of large (>106 $\mu \mathrm{m}$ fraction) denticles (elasmobranch scales; left) and fish teeth (right) from DSDP Site 596, a red clay core in the South Pacific. These ichthyoliths are approximately 52 million years old. Image was taken on the Hull Lab Imaging System, Yale University. Scale bar is $500 \mu \mathrm{m}$. 
proxy, and for rough dating of sediments (Ingram, 1995; Gleason et al., 2002, 2004, 2008). The field of ichthyolith biostratigraphy was developed in the early 1970s (Doyle et al., 1974; Edgerton et al., 1977). Composed of calcium-phosphate, ichthyoliths are extremely dissolution resistant, and are one of the last microfossil groups remaining in marine sediments exposed to corrosive bottom water and can be used to date fossil-poor pelagic red clays (Doyle and Riedel, 1979b, 1985; Doyle et al., 1988). An updated ichthyolith biostratigraphy for the Eastern North Pacific was developed in 2006 (Johns et al., 2005, 2006).

However, the Cretaceous and Cenozoic ichthyolith record can reveal important information about the role of fishes in aquatic ecosystems and their response to global change events (Sibert et al., 2014, 2016; Sibert and Norris, 2015). As ichthyoliths are found in nearly all sediment types, including those of the open ocean, which are rarely preserved on land, pelagic ichthyoliths represent a fossil record virtually untouched by traditional paleoichthyology. Further, Holocene ichthyolith records have the potential for identification to extant taxa, and can show changes in functional and taxonomic groups over prehistorical and historical time periods resulting from environmental and/or anthropogenic change (Cramer et al., 2017). For example, on modern coral reefs, the abundance of coral-associated fishes is a reliable indicator of coral abundance and growth, and intensive algal grazing by herbivorous fishes facilitates coral dominance (Randall, 1961; Bellwood and Wainwright, 2002). Thus the ichthyolith record, in conjunction with other microfossil and geochemical records, can provide insight into ecosystem response and resilience to climatic, biotic, and even anthropogenic perturbations (Sibert et al., 2014; Sibert and Norris, 2015; Cramer et al., 2017). Lastly, understanding how this group of consumers has responded to global change events may also yield insights into the mechanisms behind Cenozoic marine vertebrate evolution and the development of the vast diversity of fish clades (Nelson, 2006; Near et al., 2012, 2013; Betancur-R et al., 2013; Broughton et al., 2013).

Here, we provide a detailed methodological framework for the isolation, concentration, and analysis of ichthyoliths as a paleoceanographic, paleoecological, and paleontological resource. Although the methods presented here have been developed and tested with deep-sea sediments and near-modern coral reef sediments, we believe that they can be translated to other marine and lacustrine sediments as well.

\section{METHODS FOR ICHTHYOLITH ISOLATION AND CONCENTRATION}

We present methods for isolation of ichthyoliths from a variety of sediment types, summarized in a flow chart (Figure 2), and discuss the specifics of each protocol within the text. It is usually impractical to sort through disaggregated sediments for ichthyoliths due to their small size and rarity compared to other microfossils such as benthic and planktonic foraminifera and other coarse-grained sediment clasts. Because metrics of ichthyolith accumulation (abundance) and community structure rely on the quantification of all ichthyoliths in a sample, as opposed to a randomly sampled subset, it is necessary to concentrate the full ichthyolith assemblage from a raw sediment sample. Processing a sediment sample for ichthyoliths is a balance between efficient concentration (typically by disaggregation of sediment and washing through a fine sieve), and minimization of potential loss of teeth by dissolution, fragmentation or adherence onto surfaces such as paintbrushes, splitters, vials, or other surfaces during processing and picking. While ichthyoliths are composed of calcium phosphate (bio-apatite), which is resistant to dissolution, care must be taken to counteract potential destruction and loss of ichthyoliths when using methods of acid preparation or bleach-mediated disaggregation of sediments. Once washed, ichthyoliths are picked out of the remaining residue using a high-power dissection microscope and extremely fine paintbrush.

A challenge in working with ichthyoliths is their small size: the vast majority of teeth in pelagic sediments are only retained on a $38 \mu \mathrm{m}$ screen, passing through the typical $63 \mu \mathrm{m}$ sieves used for most foraminifera work. Modern reef fish teeth are somewhat larger, retained on $63 \mu \mathrm{m}$ screens, however they are some of the smallest-sized components of reef sediments. As a practical matter, most pelagic fish teeth are conical or triangular, and will slip through the larger $63 \mu \mathrm{m}$ sieve even if they are much longer than $63 \mu \mathrm{m}$. We have found that upwards of $50-80 \%$ of the total ichthyolith assemblage in pelagic sediments is represented by the 38-63 $\mu \mathrm{m}$ fraction in pelagic sediments. It is likely that using a sieve smaller than $38 \mu \mathrm{m}$ would yield additional ichthyoliths, as the majority of teeth in our samples are in the 38-63 $\mu \mathrm{m}$ fraction, however the $<38 \mu \mathrm{m}$ fraction presents significant technical 


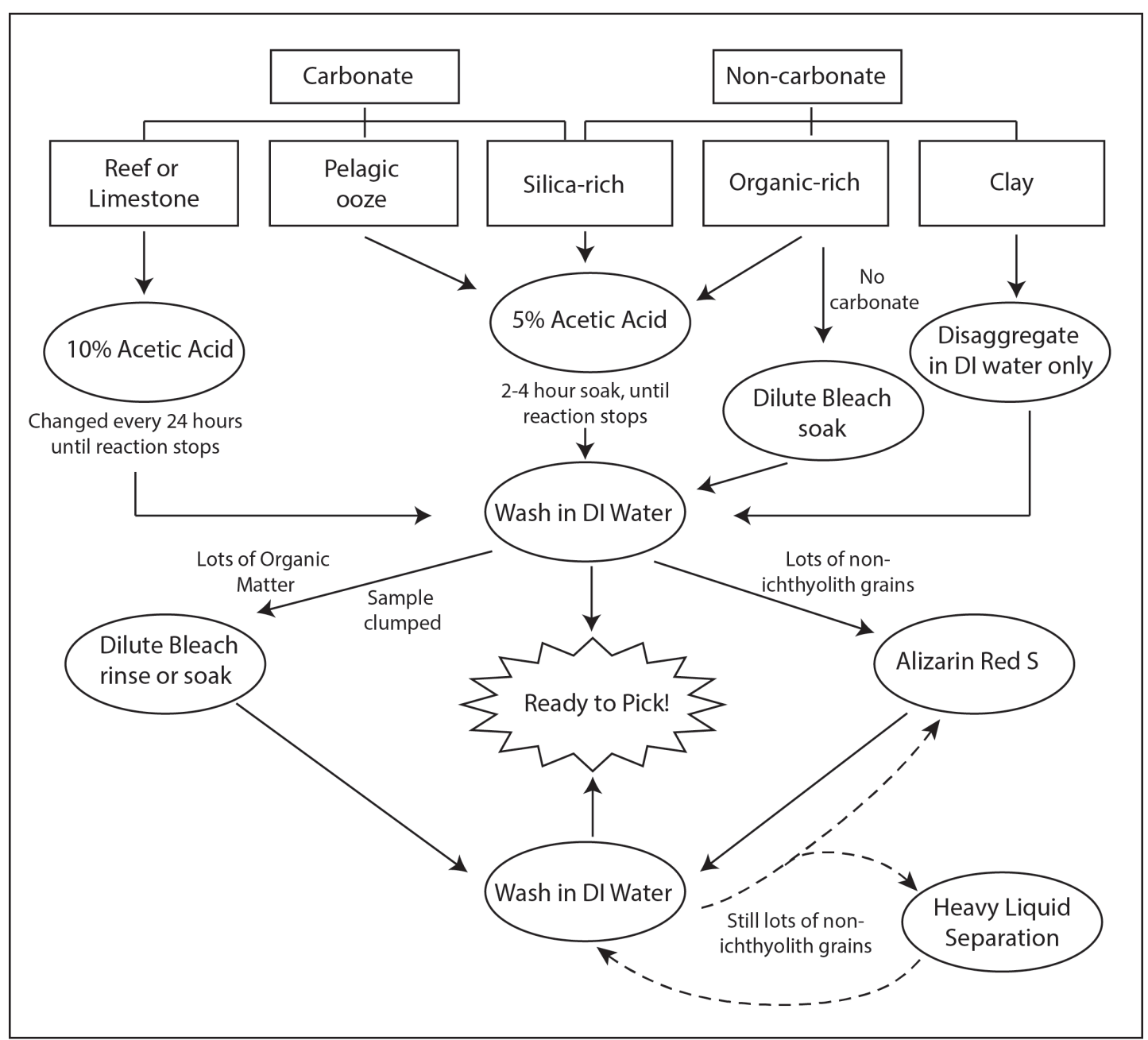

FIGURE 2. A flowchart showing the steps for sediment processing for efficient and effective ichthyolith isolation from a variety of sediment types. Sediment types are in boxes, while processing steps are shown in ovals.

challenges for reflected-light microscope-based work.

\section{Carbonates}

Acid-resistant calcium phosphate ichthyoliths can be extracted from marine carbonates by acetic acid dissolution of the calcium carbonate matrix. In deep-sea sediments, carbonate-hosted ichthyolith assemblages can be placed on the highly resolved time scales derived from analysis of other microfossil groups, magnetic reversals, or astrochronologies (e.g., Sibert et al., 2014). In Holocene coral reef sediments, high-precision uranium-thorium dating of coral skeletons can provide extremely well-resolved chronologies of fish communities over prehistorical and historical time (Cramer et al., 2017). These precise time scales provide estimates of sedimentation rate and mass accumulation rate, which can be used to estimate fish and elasmobranch abundance or productivity. Combined with the rich abundance of microfossil plankton, or the diverse hard parts of reef-associated animals, foraminifera and algae, a well-studied carbonate section can yield information about many components of an ecosystem through an interval of interest, giving environmental and ecological context to an ichthyolith record (Sibert et al., 2014; Cramer et al., 2017).

Deep-sea carbonate ooze and chalk. Simply picking ichthyoliths out of the coarse fraction of carbonate sediments is time consuming, and often leads to poor data quality, as the small teeth are obscured by the high abundance of foraminifera and siliceous microfossils. To concentrate ichthyoliths effectively and address these issues, samples are dried to a constant weight and then dissolved in $5-10 \%$ acetic acid. Acid is added to the samples in 100-200 ml increments and stirred every $\sim 20$ 
30 minutes, until no carbonate remains, usually after $\sim 2-5$ hours. The reaction is considered complete when no bubbles are released when adding acid or stirring. We find that between 30 and $80 \mathrm{ml}$ of dilute acetic acid is needed per gram of dry sediment to completely dissolve all of the carbonate in a sample, depending both on the concentration of acid used and the percent-carbonate composition of the sediments. We do not observe any etching or other damage to ichthyoliths during this process, and indeed, due to their high abundance and exceptional preservation in red clays, which were exposed to millions of years of relatively corrosive bottom water, it is unlikely that this limited exposure to weak acetic acid damages the ichthyoliths. Indeed, time-series experiments comparing acetic acid dissolution to hydrochloric acid dissolution show that while $\mathrm{HCl}$ causes significant degradation to ichthyoliths within 30 minutes of exposure, acetic acid does not harm the ichthyoliths even after prolonged soaking. However, to avoid any potential destruction of ichthyoliths, acid exposure should be limited and dilute acetic acid should be used. Once dissolved, the sample is washed over a $38 \mu \mathrm{m}$ screen, and the residue is transferred to filter paper in a funnel and dried in a $50^{\circ} \mathrm{C}$ oven.

Although it is destructive of the calcareous fossils, dissolution of bulk carbonate samples for ichthyoliths as outlined above, is by far the most effective method for ichthyolith work. It also yields the highest data quality, as every transfer of the sample between containers leads to some loss of ichthyoliths. Bulk dissolution followed by washing also uses the least amount of water per sample. However, if it is imperative to preserve certain carbonate microfossils in a sample, such as larger benthic foraminifera for isotope studies, or foraminifera from a critical interval, we suggest a doublewashing procedure: the first wash is carried out with de-ionized water only, to retain the coarse fraction of carbonates $>38 \mu \mathrm{m}$. All material below a specific size threshold (e.g., $150 \mu \mathrm{m}$ or $250 \mu \mathrm{m}$, study-specific) is then dissolved to concentrate the smaller ichthyoliths. We have found that ichthyoliths are selectively lost in sample splitters due to static adhesion and recommend against their use. As the volume of coarse-grained carbonate sediment is relatively small, it is feasible, although time consuming, to pick out all of the ichthyoliths in the $>150 \mu \mathrm{m}$ or $>250 \mu \mathrm{m}$ calcareous residues. In this case, it is most important that the processing method be internally consistent for an entire sample set, and the potential biases recognized when comparing absolute ichthyolith abundance values to other records. Additionally, large teeth $(>150$ $\mu \mathrm{m})$ are relatively rare in pelagic sediments and, if ignored or under-counted, will not greatly bias the total ichthyolith accumulation rate. Indeed, it is also possible to count only the fraction subjected to acid treatment since the fine fractions retain the vast majority of teeth in a given sample; however in this case, information on the maximum size of teeth, or the change in abundance of specific large teeth and denticles, which are almost exclusively $>100$ $\mu \mathrm{m}$ will be missed, which can preclude significant biological findings (Sibert and Norris, 2015). Therefore, the exact method employed will depend on the goals of the study. Above all, it is important to maintain consistency in processing method throughout the entire record.

Limestones. Lithified limestone also yields ichthyoliths in the acid-insoluble fraction, however, the processing is slightly different from that used for deep-sea carbonate sediments. Limestones should be broken up into $\sim 1 \mathrm{~cm}$ pieces, to increase surface area exposed to acid, while preserving the microfossils - in our experience, shatterboxes and other crushing tools can damage the fossils. Our approach comprises barely covering samples with $10 \%$ acetic acid - we have found that $5 \%$ is ineffective for the majority of limestones - and changing the acid bath every 24 hours. When changing the acid, the sample is washed over a stack of sieves with all pieces of limestone $>150 \mu \mathrm{m}$ returned to fresh acid, and all residues 38-150 $\mu \mathrm{m}$ are retained to pick through for ichthyoliths. The process takes approximately 5-12 washes, depending on the degree of lithification of the rock and the size of the original limestone fragments (Sibert et al., 2014).

Coral reef sediments. Modern reef sediments are comprised almost entirely of carbonate grains from calcifying organisms including corals, mollusks, echinoderms, foraminifera, calcareous algae, sponges, and crustaceans. To preserve these other taxonomic groups, which are mostly $>500$ $\mu \mathrm{m}$, only the fraction $<500 \mu \mathrm{m}$ of these cores is digested in acid and picked through for ichthyoliths, the majority of which are $<250 \mu \mathrm{m}$. Due to the sand to pebble-sized carbonate grains in reef sediments, $10 \%$ acetic acid is required. Two to four applications of approximately $200 \mathrm{ml}$ of acid are added to dry, size-fractioned sediments every 24 hours. When gentle stirring of acid and residues fails to cause further reaction and residues darken due to dominance of organic material following elimination of carbonates, samples are transferred to a $63 \mu \mathrm{m}$ sieve and washed with $\mathrm{DI}$ water until the water 
leaving the sieve runs clear. Coral reef sediments often have considerable organic matter and debris, which causes excessive clumping of ichthyoliths and highly abundant but acid-insoluble siliceous sponge spicules. To remove excess organic matter, the washed samples can be treated with $25 \mathrm{ml}$ dilute chlorine bleach poured directly onto the sieve following an initial wash, left for approximately 1 minute, then rinsed with DI water and lightly agitated until water runs clear below the sieve. The samples are then transferred to filter paper in a funnel and dried at $50^{\circ} \mathrm{C}$. In contrast to pelagic sediments, where the majority of ichthyoliths are within the 38-63 $\mu \mathrm{m}$ fraction, the vast majority of ichthyoliths preserved in reef sediments are $>63 \mu \mathrm{m}$, so the $63 \mu \mathrm{m}$ sieve size is used to facilitate washing the larger initial sample volumes necessary in these high sedimentation rate systems (Cramer et al., 2017).

\section{Pelagic Clays}

Pelagic clays yield, by far, the greatest abundance of ichthyoliths per gram sediment: the slow sedimentation rate below the carbonate compensation depth, and small grain size means that ichthyoliths are highly concentrated, and are typically well-preserved in these sediments. However, the slow sedimentation rate and lack of other biostratigraphically well-calibrated microfossils such as calcareous nannofossils, mean that clays often have poor age constraints, and there may be very little paleoenvironmental context from traditional proxies.

To isolate ichthyoliths from pelagic clay, the samples are dried completely to enable the calculation of ichthyolith accumulation rates. We have found that many pelagic clay samples fail to achieve stable dry weights for many weeks, perhaps because of water bound in clays. However, once the samples are completely dried, they are simply disaggregated in de-ionized water, washed over a $38 \mu \mathrm{m}$ sieve, transferred to filter paper in a funnel, dried in a $50^{\circ} \mathrm{C}$ oven, and examined under the microscope. These residues, in the best circumstance, may contain only fish teeth and dermal denticles, however, in some cases may also contain micro-Manganese nodules, siliceous microfossils, terrigenous sediment clasts, zeolites, or clumps of Fe-oxides.

\section{Silica-dominated Sediments}

Siliceous sediments, whether from quartz silt or biogenic opal, create a distinctive challenge in the isolation and quantification of ichthyoliths. Sil- ica is insoluble in acetic acid and thus increases the volume of the acid-insoluble coarse-fraction containing ichthyoliths. Additionally, many quartz grains have a significant visual similarity to tiny ichthyoliths at first glance, making visual identification and picking a challenge. We have found two methods to be effective in isolation of teeth in siliceous sediments-the use of Alizarin Red S, a calciumspecific stain to color ichthyoliths and make them visible against a backdrop of translucent silica. For particularly challenging samples, heavy liquid separation may remove most of the low density siliceous sediment relative to ichthyoliths, however, we do not recommend this as a first line of ichthyolith concentration methods.

Alizarin Red S. Visual differentiation of fish teeth from other small triangular sediment grains can often be confounded at small size fractions $(<63$ $\mu \mathrm{m})$. However, ichthyoliths can be preferentially stained by Alizarin Red S (1,2-dihydroxyanthraquinone, $\mathrm{C}_{14} \mathrm{H}_{8} \mathrm{O}_{4}$ ), a calcium-specific dye commonly used in clearing-and-staining fish (Taylor, 1967; Song and Parenti, 1995). Alizarin Red S gives ichthyoliths a pink tinge, while leaving the silica grains untouched (Figure 3). Alizarin is a $\mathrm{pH}$ sensitive dye, which turns a deep purple in basic solution, and when in contact with calcium, will adhere to it, leaving a pink or red color. Alizarin Red $S$ is not a panacea: it will also dye calcium carbonate grains, and thus is used most effectively after the carbonate fraction has been removed from a sample via acid dissolution (see Figure 2). However we have found that even in samples with carbonate, ichthyoliths are preferentially stained a more intense color than foraminifera. We modified a clearingand-staining protocol for fishes, based on both a published protocol (step 9, Song and Parenti, 1995), and the protocol used by Scripps Marine Vertebrate Collection, to use a $1 \%$ potassium hydroxide $(\mathrm{KOH})$ solution with enough Alizarin to turn the solution a deep purple (a surprisingly small amount). The $\mathrm{KOH} /$ Alizarin Red $\mathrm{S}$ solution is added to the post-acid, washed and dried residue. The volume of Alizarin $+\mathrm{KOH}$ solution needed is dependent on the amount of residue: generally, just a few drops of the solution, enough to cover the sample residue in its container, is more than sufficient to produce the desired effect. This is left for 24 to 48 hours, and then washed over a $38 \mu \mathrm{m}$ screen, transferred to filter paper in a funnel, and dried overnight in a $50^{\circ} \mathrm{C}$ oven before picking. This technique is extremely effective, staining $>95 \%$ of the ichthyoliths in a sample a pink color (Figure 3). The intensity of the color is dependent on both the 

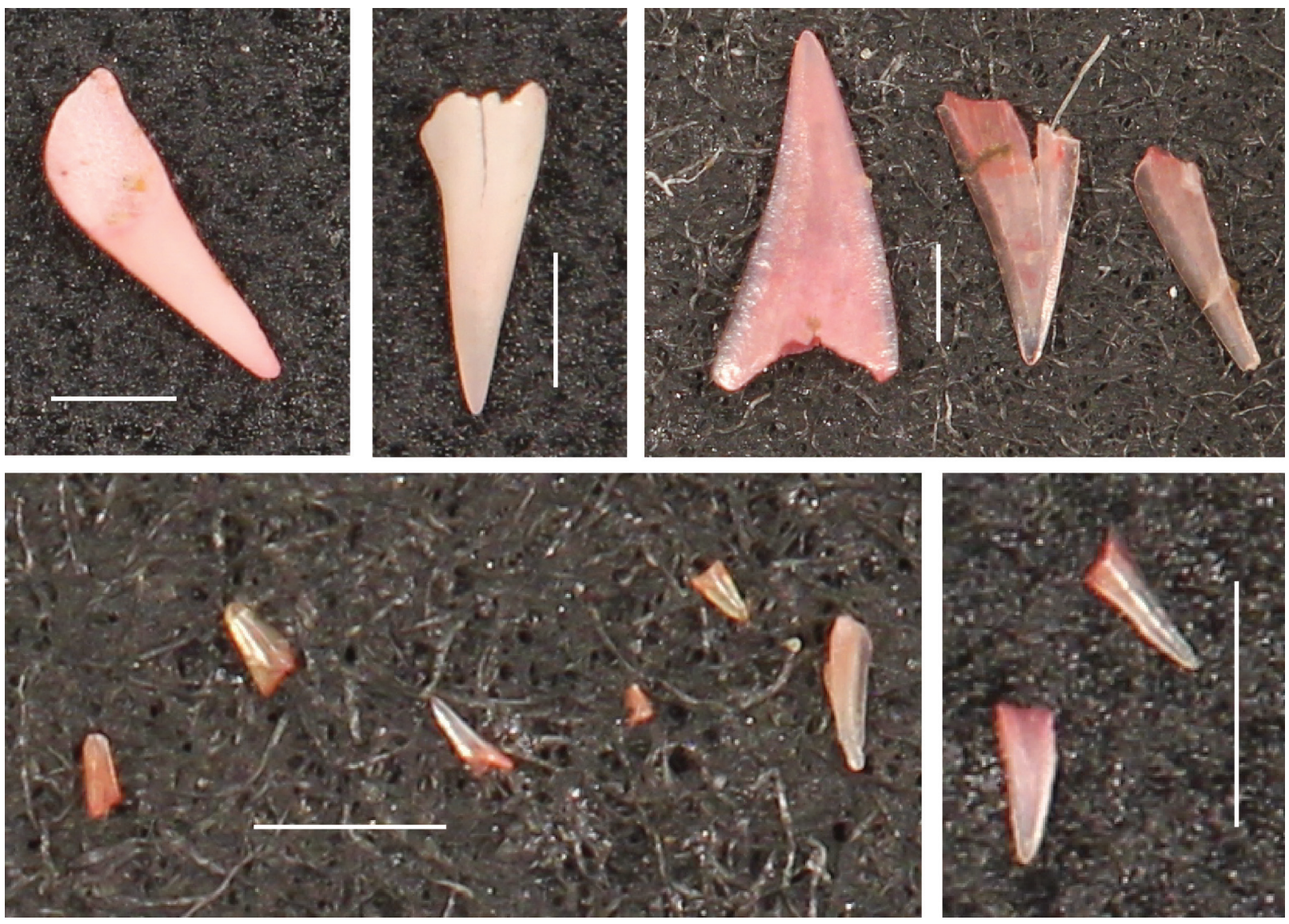

FIGURE 3. Paleocene-aged ichthyoliths from ODP Site 1262, stained with Alizarin Red S. The scale bar is $500 \mu \mathrm{m}$, with teeth $>106 \mu \mathrm{m}$ in the upper row and teeth $<106 \mu \mathrm{m}$ in the lower. Note that in the coloring effect is present in all teeth, however, the degree of staining varies.

concentration of dye, and the length of time in solution. Time step experiments have shown that the Alizarin protocol does not cause physical degradation of the teeth, even after weeks in the solution, though the color gets progressively darker. However, as the Alizarin staining protocol requires toxic chemicals $(\mathrm{KOH})$ and a second wash, which can increase the amount of teeth lost to processing, it is generally best saved for particularly challenging residues, where silica consistently confounds counts of small ichthyoliths and used consistently within a single record.

Heavy liquid separation. Heavy liquids have been historically used to isolate calcium phosphate conodonts from acid-prepared limestone, and the methods have been described extensively elsewhere (Leiggi and May, 2005). This procedure can effectively separate ichthyoliths from biogenic silica and quartz silt, however heavy liquids are expensive and often toxic, making them a last resort for ichthyolith isolation. We have used both sodium metatungstate hydrate $\left(\mathrm{Na}_{6} \mathrm{~W}_{12} \mathrm{O}_{39} \times \mathrm{xH}_{2} \mathrm{O}\right)$ and LST solution (heteropolytungstate) as heavy liquids since both are non-toxic and have low viscosity at room temperature. Both liquids have the disadvantage of being relatively expensive $(\sim \$ 1000 /$ iter $)$ and can be destroyed by contamination with calcium. Therefore, the use of heavy liquids on samples containing calcium carbonate grains should be avoided. We use a heavy liquid density of about $2.3-2.4 \mathrm{~g} / \mathrm{cm}^{3}$ to capture most of the biogenic silica or $2.85 \mathrm{~g} / \mathrm{cm}^{3}$ to separate ichthyoliths from quartz silt.

In our practice, heavy liquid of suitable density is poured into a $25-50 \mathrm{~mL}$ tube containing the prepared sample residues and mixed until the sample is completely wetted; sufficient heavy liquid should be added to the tube so that the silica can float. The tube is capped and centrifuged for five minutes at 1000-1500 rpm to concentrate the ichthyoliths in the bottom of the tube. The light fraction is scooped or poured off the top of the liquid. Both the light and heavy fractions are rinsed in de-ionized water over a $38 \mu \mathrm{m}$ screen, retaining the rinse solution, then transferred to filter paper in a funnel and dried in at 
$50^{\circ} \mathrm{C}$ oven. The dilute heavy liquid is recovered and cleaned by passing it through a $0.4 \mu \mathrm{m}$ filter in a vacuum filtration system, and then placed in an oven to evaporate the rinse water and restore its density.

\section{Organic Rich Sediments}

While the majority of deep-sea sediments are carbonate or silica-dominated, there are distinct horizons, such as the Mediterranean sapropels (Cramp and O'Sullivan, 1999), which are organicrich, and ichthyolith concentration using other methods is hampered. In addition, modern coral reef sediments, though carbonate dominated, may still have considerable amounts of organic matter. Organic matter can lead to sediment clumping and adds extra challenges to sample processing. To address this, samples are first disaggregated and dissolved in weak acid, following the carbonate deep-sea sediments or coral reef sediments protocols (see Figure 2), and washed over a $38 \mu \mathrm{m}$ sieve. However, in the case of high organic matter content, there may be numerous organic-rich clumps of sediment remaining. Once the sample has been thoroughly washed, a rinse while on the sieve with dilute $(5-10 \%)$ bleach solution promotes disaggregation and dissolution of the remaining organic matter. However, it is important to note that bleach and acetic acid produce chlorine gas when mixed, so caution is advised to ensure that the sample is sufficiently rinsed from acid before any bleach is used.

In the case where disaggregation of organicrich sediments does not occur with the addition of de-ionized water or acetic acid, an additional short soak in bleach, hydrogen peroxide $\left(\mathrm{H}_{2} \mathrm{O}_{2}\right)$, Borax $^{\mathrm{TM}}$, Calgon ${ }^{\mathrm{TM}}$, or OxiClean ${ }^{\mathrm{TM}}$ are a potential alternatives, although prolonged exposure to any of these chemicals can damage the ichthyoliths. Most commercial grades of bleach contain perfume and colorants besides pure sodium hypochlorate, and various formulations produce different results. For instance, in work with Turonian black shales from Ocean Drilling Program Site 1259, we achieved the best disaggregation using pure commercial bleach, rather than making a dilute mixture (Bice and Norris, 2005). In our experience, commercial grades of bleach vary in their content of sodium hypochlorate from $5.25 \%$ to $6 \%$. Dilution lowers the $\mathrm{pH}$ of bleach solutions, potentially increasing the etching of microfossils with sustained contact and may reduce the effectiveness of the solution for breaking down organic-rich sediments. However, prolonged exposure to bleach at any concentration is potentially damaging to the organic components in ichthyoliths and should be limited if possible.

Isolating modern ichthyoliths. Similar to removing organic material from sediments, flesh can be removed from jaws or skin patches of modern specimens to isolate taxonomically known fish teeth and shark scales. In this case, the jaw (for fish teeth) or a patch of skin (for shark denticles) is dissected from a modern specimen and placed in dilute $(5-10 \%)$ bleach until all flesh is dissolved, usually 1-4 hours. Since bleach will attack the organic compounds in teeth and bone as well as the softer tissues, we recommend removing the ichthyoliths from the bleach and washing the newly isolated modern ichthyoliths as soon as is practical. These isolated modern ichthyoliths are then washed over a $38 \mu \mathrm{m}$ screen and dried in at $50^{\circ} \mathrm{C}$ oven.

\section{Comments about Ichthyolith-specific Washing and Picking Techniques}

Traditional uses of ichthyoliths, for biostratigraphy or as carriers of isotopes, do not require that all teeth be retained and accounted for in a sample. However, to assess the ichthyolith accumulation rate, ichthyolith community structure, and the role of fishes within an ecosystem through time, all of the ichthyoliths within a certain size range must be quantified. The methods presented here aim to improve the fidelity of isolation and concentration of ichthyoliths, to make this robust quantification both possible and repeatable. Due to their small size and unusual shape, care must be taken when handling the concentrated ichthyolith residue to avoid losing any teeth. As most teeth are triangular, they tend to stick point-down into the sieve when washing. Running water up through the back of the sieve, a technique often used when separating biological samples, will help to dislodge any teeth that are stuck point-down.

Earlier ichthyolith work mounted tooth residues in optical medium and viewed them using transmitted light microscopy (Doyle et al., 1977; Doyle and Riedel, 1979a, 1979b, 1985). Transmitted light imaging is particularly useful for observing the details of the interior of the pulp cavity and the structure of the enamel cap and may have value for identification of teeth to taxonomic group (Doyle and Riedel, 1979b; Johns, 1993). Strewn slides made by embedding the entire sample residue in Canada Balsam or Norland optical medium can also be used to count the abundance of extremely small teeth, which can be re-located by use of a 
England Finder, similar to the study of calcareous nannoplankton. However, there are a number of disadvantages of embedding teeth in a mounting medium, including the formation of bubbles in the pulp cavity, the difficulty in achieving standard orientations given the very small size of many teeth, and the three-dimensional aspect of large teeth in contrast with the narrow depth of field in transmitted light microscopy. An alternative approach is to pick ichthyoliths with a fine paint brush and mount them with water soluble glue on cardboard micropaleontology slides. This method retains the most options for quantifying ichthyoliths. It also ensures that teeth are not overlooked in original count analyses. Once picked, these assemblage slides are a resource, which can be worked with directly or easily be used for many other imaging techniques, including transmitted light microscopy, scanning electron microscopy, and even microCT or nanoCT scanning. This also leaves the ichthyoliths accessible for geochemical analyses.

\section{BIOLOGICAL ICHTHYOLITH METRICS}

\section{Fish Production: Ichthyolith Accumulation Rates}

Once isolated and quantified, ichthyoliths provide a unique view of fish production and community dynamics through time. However, changes in sedimentation rate as well as sediment composition and density can have a profound effect on the absolute abundance of ichthyoliths in a sample, which bias any estimations of fish production or flux. To correct for this, we calculate an ichthyolith accumulation rate (IAR; eq. 1), yielding a metric of ichthyolith flux of ichthyoliths falling to a fixed area of seafloor over a fixed time interval. Thus, changes in IAR can be interpreted as increases or decreases in total ichthyolith production, a proxy for overall fish production (Sibert et al., 2014, 2016; Sibert and Norris, 2015). IAR in pelagic sediments is calculated as:

Ichthyolith Accumulation Rate = Abundance ${ }^{*}$ Dry Bulk Density * Sedimentation Rates

$$
\left(\frac{\text { Ichthyoliths }}{\mathrm{cm} 2 \cdot \mathrm{kyr}}\right)=\frac{\text { ichthyoliths }}{\mathrm{gram}} \cdot \frac{\text { grams }}{\mathrm{cm} 3} \cdot \frac{\mathrm{cm}}{\mathrm{kyr}}
$$

In the case of sediments from reef matrix cores, which have large fragments of subfossil coral or mollusk shell (>2 mm), IAR is calculated by normalizing by the weight of sediments in the size fraction $<2 \mathrm{~mm}$ (where the vast majority of teeth are found) and the number of years represented by a sample. The number of years in a sample can be computed from U/Th-derived sediment accumulation rates (Cramer et al., 2017). This produces an ichthyolith abundance accumulation rate (AAR):

$$
\begin{gathered}
\text { AAR }=\left(\frac{\text { Ichthyoliths }}{\text { gram } \text { year }}\right) \\
\text { equals } \\
\text { ichthyoliths } / \frac{\text { years }}{\text { sample }} / \text { grams }
\end{gathered}
$$

This calculation of IAR or AAR normalizes for sedimentation rate and changes in lithology. Therefore, we can compare the flux of ichthyoliths to the sea floor between sites with very different background sedimentation rates, such as between open ocean gyre sites and those from the high-productivity equatorial oceans. We can also correct for variations in sedimentation rate time in a single site that result from changes in fish production, sediment delivery, or carbonate dissolution. However, the calculation of accumulation rate is highly sensitive to the accuracy of the time scale used to estimate sedimentation rate. Bulk density is also a component of accumulation rate, but contributes relatively little to variation in accumulation rate in most pelagic sediments (see supplement to Sibert et al., 2014). An exception is where there are major changes in lithology, such as from carbonates to claystone or calcareous ooze to limestone; in these cases accurate measurement of bulk density and sedimentation rate can be important in the calculation of accumulation.

Sample size. The size fractions quantified can be study-specific, to balance between statistical confidence in the data (enough ichthyoliths available), time committed by the researcher, and preservation of other microfossils. We have found through our work that for pelagic marine carbonates, where sedimentation rate is $1-2 \mathrm{~cm} / \mathrm{kyr}$, quantification of all ichthyoliths $>38 \mu \mathrm{m}$ in a $10-20 \mathrm{cc}$ sample is necessary for sufficiently robust abundances of $>30$ 100 teeth/sample. The same sample volume in pelagic red clay can yield hundreds to thousands of teeth, and statistically significant samples of several hundred teeth may be found in the $>106 \mu \mathrm{m}$ fraction. In contrast, in coastal sediments and reef carbonates, the high degree of dilution of ichthyoliths by other grains and higher sedimentation rates can require much larger sample volumes to obtain statistically representative ichthyolith samples. For example, in our work in modern Caribbean reef sediments, we routinely sample volumes of $400 \mathrm{cc}$ 
(about $200 \mathrm{~g}$ dry weight) to recover a range of 2 to 250 teeth (mean $=74$ teeth) and 0-5 denticles per sample.

While the abundance of fish may be an indicator of primary or export productivity of an ecosystem, this is not the only signal recorded in the ichthyolith record. The overall efficiency of a marine food web is determined by how many trophic steps are needed to transfer the carbon fixed by primary producers up to higher-order consumers such as fish. In a large phytoplankton-dominated system, such as a modern upwelling zone, a modest primary production will yield abundant fish with only 1-2 trophic steps. In contrast, a system dominated by small phytoplankton (such as cyanobacteria in the open ocean) can require 5-7 trophic steps to produce a single fish (Moloney and Field, 1991; Moloney et al., 1991). While both of these ecosystems may have similar levels of primary production, the former will produce several orders of magnitude more fish biomass than the latter (Iverson, 1990) and thus should have a significantly higher ichthyolith accumulation rate. Indeed, a substantial portion of observed IAR patterns could be accounted for not by changing net primary production, but instead by small shifts in the relative abundance of certain size classes of phytoplankton. This food web imprint can also be exacerbated by changes in the efficiency of energy transfer between trophic levels due to increases or decreases in metabolic rates of the organisms. Accumulation rates may be also be affected by changes in habitat: for example, in coral reef sediments, abundances of teeth from coral-associated taxa are tightly coupled with reef accretion rates (Cramer et al., 2017).

Ichthyolith accumulation is also influenced by the production of ichthyoliths by individuals. Species which put considerable effort into growing their teeth and have low turnover, or resorb teeth rather than shedding them (Bemis et al., 2005), could produce fewer ichthyoliths than a species which produces numerous, but oftentimes less sturdy teeth which are regularly shed. The majority of the ichthyolith accumulation rate signal is driven by the smallest teeth, which likely are derived from a combination of small species, juvenile fish, and the pharyngeal tooth battery. At present we are unsure about the relative contribution of teeth from these different sources, but we suspect that most teeth preserved in sediments are biased toward those with dissolution-resistant enamel caps. The excellent preservation of enamel relative to dentine is likely to bias the tooth record toward oral teeth, and those of species with robust dentitions, and mitigate against relatively lightly calcified pharyngeal teeth and the teeth of some midwater species where an elongate pulp cavity can run almost the full length of the teeth (Fink, 1981). Indeed, longterm trends in changes in ichthyolith abundance, particularly those associated with shifts in the size structure of the assemblage, may reflect an evolutionary shift in fish community composition, (e.g., those documented in Sibert and Norris, 2015 and Sibert et al., 2016), rather than a change in overall primary productivity or food web dynamics.

\section{Fish Community Structure: Ichthyolith Assemblage Metrics}

While taxonomic identifications of most ancient ichthyoliths are presently elusive, a considerable amount of information about marine vertebrate community composition can be obtained by considering the composition of whole ichthyolith assemblages, which preserve snapshots of the entire community, rather than occurrences of a single species or morphotype. Since ichthyoliths are abundant in most sediment samples, we can evaluate how the relative abundances of different marine vertebrate groups have changed through time.

Vertebrate community structure. Due to similarity in their chemical compositions, both elasmobranch dermal scales (denticles) and ray-finned fish teeth are preserved in the ichthyolith record. While the majority of denticles preserved in the ichthyolith record have been chipped, or preserve only the enamel crown of the scale, they are distinctive from teeth and readily recognizable as denticles (Figure 1). The relative and absolute abundances of teeth and denticles through time can be used to study the response of different trophic level organisms to global change (Sibert and Norris, 2015; Sibert et al., 2016).

Ichthyolith functional group and taxonomic composition. Individual ichthyolith size is also informative of evolutionary patterns. While fish tooth size is not necessarily correlated directly with body size (e.g., deep-sea viperfish of the family Stomiidae have fanglike teeth that are nearly the length of their head), it is an indicator of diet. For example, long, pointed teeth are more likely to be used for handling larger or more active prey. The size structure of an ichthyolith assemblage, quantified either through changes in relative abundance of different size fractions or by measuring the length of individual teeth (Sibert and Norris, 2015), can reveal evolutionary or ecological trends. For 

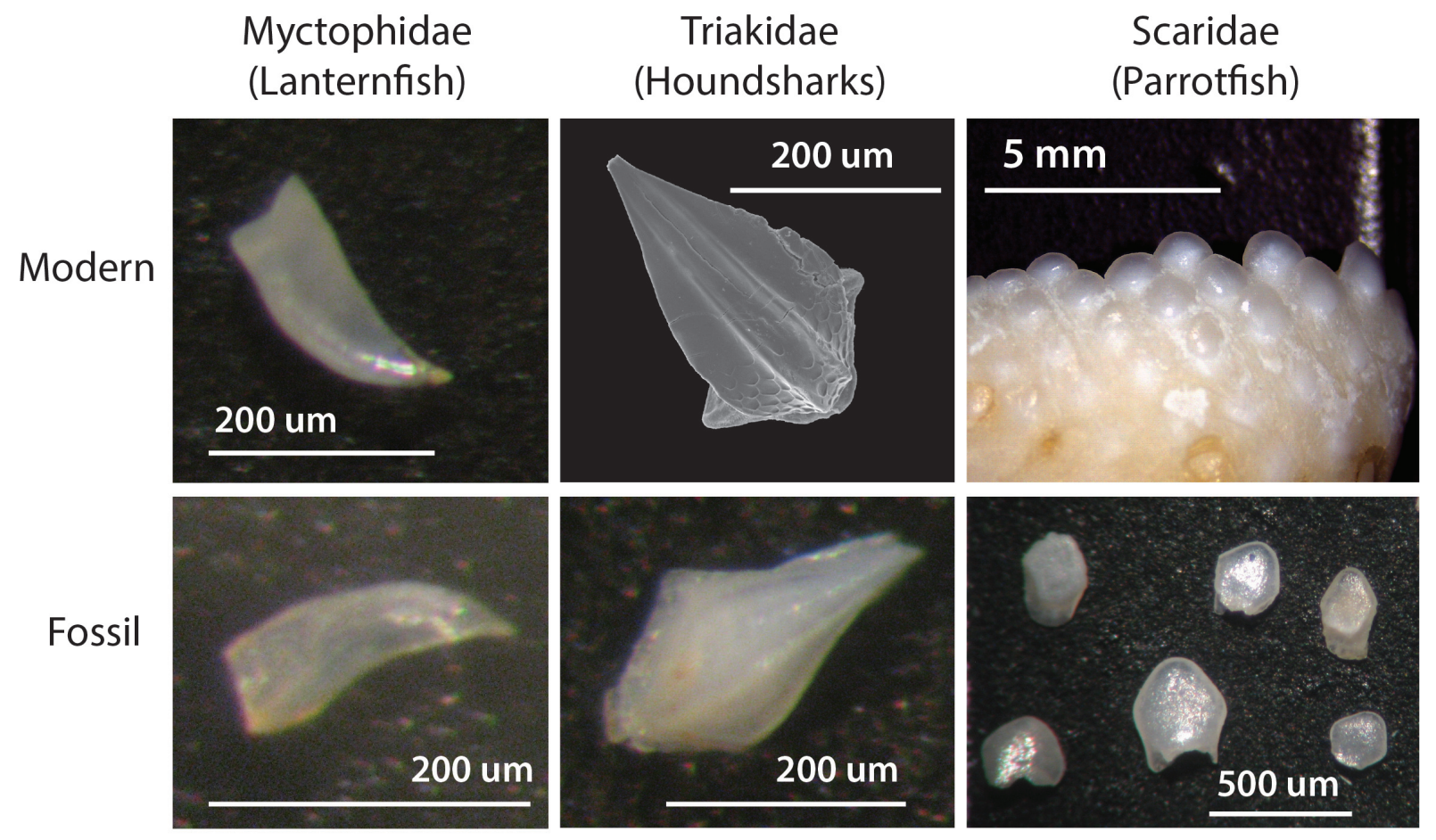

FIGURE 4. Examples of select taxonomically identifiable fossil ichthyoliths and modern counterparts. All modern ichthyoliths were isolated from specimens in the Scripps Marine Vertebrate Collection. The fossil Myctophidae and Triakidae specimens are from ODP Site 1262, and are 62 million years old. The Scaridae modern teeth are from Smithsonian National Museum of Natural History's Fish Collection and subfossil teeth are from coral reef sediment cores taken off of the coast of Bocas del Toro, Panama, and are approximately 1200 years old.

example, following the Cretaceous-Paleogene extinction, the maximum size of the largest teeth in an assemblage in open ocean sediments tripled from pre-extinction values, suggesting that there was a radiation of fishes preferring larger prey following the extinction event (Sibert and Norris, 2015).

While some ichthyoliths are taxonomically identifiable (Figure 4), the majority remain unidentified to taxonomic group at present. Teeth from modern Caribbean reef sediments have a greater variety of tooth morphotypes than those from pelagic sediments and can be divided into diet categories such as predators (raptorial or canine teeth), herbivores (incisiform teeth), and durophagous invertivores (molariform teeth), producing a record of fish trophic structure through time (Cramer et al., 2017). Utilizing a fish tooth reference collection for modern Caribbean reef fish (www.ichthyolith.ucsd.edu), it is also possible to identify several distinctive tooth types to family level. Pelagic ichthyoliths also have discrete morphological characters, such as the shape and structure of the pulp cavity, which have been studied in depth for bio- stratigraphy, and we believe that identification of either taxonomic affinity or ecological group will also become possible for pelagic fishes as research progresses.

Ichthyolith taphonomy. While ichthyoliths are generally resistant to the dissolution effects that damage other microfossil groups, there are several taphonomic processes that can affect the preservation of ichthyoliths. It is rare to find highly fragmented samples, and ichthyoliths rarely display pitting or other signs of partial dissolution. However, as many large teeth have an extensive, hollow pulp cavity, these teeth are prone to splitting due to mechanical forces, either during preservation or laboratory sediment processing. As the large teeth most likely to break are relatively rare in a sample, it is often straightforward to piece a single large tooth back together following a fracture. We have also occasionally observed iron and manganese oxides growing in the pulp cavity of teeth which can also cause splintering. These same oxides can also grow around teeth, hiding them from observation. Finally, some parts of ichthyoliths are more durable than others. For example, the 
crowns of denticles are much more likely to be preserved than the subcutaneous base, and the more heavily enameled tooth tips preserve more often as well. Despite these potential taphonomic biases, the ichthyolith record is generally well-preserved.

Future applications of ichthyoliths. While we have addressed several applications of the ichthyolith record here, there are numerous other potential applications. For example, taxonomically identifiable pelagic ichthyoliths can provide significantly better fossil calibration ages for molecular clock estimates of divergence in open ocean fish lineages, which have a poor body fossil record. Comparison of ichthyolith records with other biological groups present in the same core (e.g., ichthyoliths and coral community composition in the Caribbean, or fish and foraminifera in the open ocean) can reveal trophic or community dynamics through time. IAR or community composition metrics can also be compared to geochemical proxies, to assess the effects of local or global change on fish population or community ecology. Establishing the natural abundance, structure, and variability of fish communities in coastal, reef, or even lake settings, on historic or pre-historic timescales can provide a baseline for separating anthropogenic pressures and climate impacts on economically significant fish stocks. Finally, archaeological middens may have considerable amounts of ichthyoliths, which could offer insight into how ancient humans interacted with marine resources. However, archaeological practice commonly studies only the $>5 \mathrm{~mm}$ fraction in screen washings, which will fail to recover virtually all teeth (e.g., Powell, 2003; Rainsford et al., 2014). Hence, future archaeological use of ichthyoliths will require preserving at least a known proportion of the fine material ordinarily discarded during screen washing.

\section{CONCLUSIONS}

Ichthyoliths represent an important and understudied microfossil group that preserves the record of fishes and sharks at unprecedented temporal resolution. Quantification of the relative and absolute abundance of ichthyoliths through time can reveal changing patterns in fish production, food web stability, and ecosystem structure through Earth's history (including the Anthropocene) and across global change events throughout much of the Phanerozoic. Accurate quantification of these trends in ichthyolith accumulation and assemblage structure relies on quantification of all ichthyoliths in each discrete sample. We have presented a methodological framework for isolation and quantification of ichthyoliths from most marine sediment types ranging from coral reefs to the open ocean, however, these methods can also be applied to lacustrine or other aquatic deposits. We have further presented a novel protocol for staining ichthyoliths pink for easier and more accurate visual identification using Alizarin Red S. The applications of the ichthyolith record include more traditional biostratigraphy and geochemistry, alongside fish production, evolution, and ancient food web reconstruction. Taxonomic or ecological identification of ichthyoliths will further reveal patterns in fish evolution, shed light on the development and rise to dominance of the most diverse group of vertebrates on the planet, and reveal the full magnitude of change in fish communities resulting from past and present human activities.

\section{ACKNOWLEDGMENTS}

We thank J. Williams, K. McComas, D. Pitassy, H.J. Walker, M. Alvarez, F. Rodriguez, M.P. Concepcion, and A. Castillo for help with developing the modern Caribbean reef fish tooth reference collection; A. Sanderson and D. Chen for help with isolating and identifying teeth from coral reef cores; B. Oller, C. Carpenter, S. Buckley, and M. Siltanen for help processing reef sediments; and J. Lyakov for help with tooth dissolution experiments. E.C.S. was supported on an NSF Graduate Research Fellowship. K.L.C. was supported by Smithsonian Institution MarineGEO Postdoctoral Fellowship and UC San Diego Frontiers of Innovation Scholars Postdoctoral Fellowship. No permits were required for the described study, which complied with all relevant regulations.

\section{REFERENCES}

Bellwood, D.R. and Wainwright, P.C. 2002. The history and biogeography of fishes on coral reefs, p. 5-32. In Sale, P.F. (ed.), Coral Reef Fishes: Dynamics and Diversity in a Complex Ecosystem. Academic Press, San Diego.

Bemis, W.E., Giuliano, A., and McGuire, B. 2005. Structure, attachment, replacement and growth of teeth in bluefish, Pomatomus saltatrix (Linnaeus, 1766), a teleost with deeply socketed teeth. Zoology, 108:317327.

Betancur-R., Broughton, R.E., Wiley, E.O., Carpenter, K., López, J.A., Li, C., Holcroft, N.I., Arcila, D., Sanciangco, M., and Cureton, J. 2013. The tree of life and a new classification of bony fishes. PLoS Currents, 5:1-33.

Bice, K.L. and Norris, R.D. 2005. Data report: Stable isotope ratios of foraminifers from ODP Leg 207, Sites 
1257, 1258, and 1260 and a cleaning procedure for foraminifers in organic-rich shales. Proceedings of the Ocean Drilling Program Scientific Results, 207. Available at http://www-odp.tamu.edu/publications/ 207_SR/104/104.htm. doi:10.2973/ odp.proc.sr.207.104.2005

Broughton, R.E., Betancur, R., Li, C., Arratia, G., and Ortí, G. 2013. Multi-locus phylogenetic analysis reveals the pattern and tempo of bony fish evolution. PLoS Currents, 5, ecurrents.tol.2ca8041495ffafd0c92756e 75247483 e.

Cappetta, H. and Schultze, H. 2012. Mesozoic and Cenozoic Elasmobranchii: teeth, chondrichthyes, p. 1-512. In Schultze, H. (ed.). Handbook of Palaeoichthyology, 3E. Verlag Publishing, Munich.

Cifelli, R. 1969. Radiation of Cenozoic planktonic foraminifera. Systematic Biology, 18:154-168.

Cramer, K.L., O'Dea, A., Clark, T.R., Zhao, J., and Norris, R.D. 2017. Prehistorical and historical declines in Caribbean coral reef accretion rates driven by loss of parrotfish. Nature Communications, 8:14160. doi: $10.1038 /$ ncomms 14160

Cramp, A. and O'Sullivan, G. 1999. Neogene sapropels in the Mediterranean: a review. Marine Geology, 153:11-28.

Doyle, P., Kennedy, G.G., and Riedel, W.R. 1974. Stratigraphy. p. 825-905. Thomas, D.A. (ed.), Initial Reports of the Deep Sea Drilling Project, 26, Durban, South Africa to Fremantle, Australia, September-October 1972. National Science Foundation, Washington D.C.

Doyle, P.S., Boillot, G., Winterer, E.L., Meyer, A.W., Applegate, J., Baltuck, M., Bergen, J.A., Comas, M.C., Davies, T.A., Dunham, K.W., Evans, C.A., Girardeau, J., Goldberg, D., Haggerty, J.A., Jansa, L.F., Johnson, J.A., Kasahara, J., Loreau, J.-P., Luna, E., Moullade, M., Ogg, J.G., Sarti, M., Thurow, J., and Williamson, M.A. 1988. Remarks on Cretaceous-Tertiary ichthyolith stratigraphy in the Atlantic, Ocean Drilling Program Leg 103. Proceedings of the Ocean Drilling Program, Scientific Results, 103:445-458.

Doyle, P.S., Dunsworth, M.J., and Riedel, W.R. 1977. Reworking of ichthyoliths in eastern tropical Pacific sediments. Deep-Sea Research, 24:181-198.

Doyle, P.S. and Riedel, W.R. 1979a. Cretaceous to Neogene ichthyoliths in a giant piston core from the central North Pacific. Micropaleontology, 25:337-364.

Doyle, P.S. and Riedel, W.R. 1979b. Ichthyoliths: Present Status of Taxonomy and Stratigraphy of Microscopic Fish Skeletal Debris. Scripps Institution of Oceanography Reference Series, 79-16. Scripps Institution of Oceanography, University of California, San Diego.

Doyle, P.S. and Riedel, W.R. 1985. Cenozoic and Late Cretaceous Ichthyoliths. Plankton Stratigraphy. Cambridge University Press, Cambridge.

Edgerton, C.C., Doyle, P.S., and Riedel, W.R. 1977. Ichthyolith age determinations of otherwise unfossilifer- ous Deep Sea Drilling Project cores. Micropaleontology, 23:194-205.

Fink, W.L. 1981. Ontogeny and phylogeny of tooth attachment modes in actinopterygian fishes. Journal of Morphology, 167:167-184.

Frerichs, W.E. 1971. Evolution of planktonic foraminifera and paleotemperatures. Journal of Paleontology, 45:963-968.

Friedman, M. and Sallan, L.C. 2012. Five hundred million years of extinction and recovery: a Phanerozoic survey of large - scale diversity patterns in fishes. Palaeontology, 55:707-742.

Gleason, J., Moore, Jr. T., Johnson, T., Rea, D., Owen, R., Blum, J., Pares, J., and Hovan, S. 2004. Age calibration of piston core EW9709-07 (equatorial central Pacific) using fish teeth $\mathrm{Sr}$ isotope stratigraphy. Palaeogeography, Palaeoclimatology, Palaeoecology, 212:355-366.

Gleason, J.D., Moore, T.C., Rea, D.K., Johnson, T.M., Owen, R.M., Blum, J.D., Hovan, S.A., and Jones, C.E. 2002. Ichthyolith strontium isotope stratigraphy of a Neogene red clay sequence: calibrating eolian dust accumulation rates in the central North Pacific. Earth and Planetary Science Letters, 202:625-636.

Gleason, J.D., Thomas, D.J., Moore, T.C., Blum, J.D., Owen, R.M., and Haley, B.A. 2008. Early to middle Eocene Arctic paleoceanography from $\mathrm{Nd}$-Sr isotope study of fossil fish debris, Lomonosov Ridge. Geochimica et Cosmochimica Acta, 72:A314.

Hallock, P. and Schlager, W. 1986. Nutrient excess and the demise of coral reefs and carbonate platforms. Palaios, 1:389-398.

Hilgen, F. 1991. Astronomical calibration of Gauss to Matuyama sapropels in the Mediterranean and implication for the geomagnetic polarity time scale. Earth and Planetary Science Letters, 104:226-244.

Hilgen, F.J., Kuiper, K.F., and Lourens, L.J. 2010. Evaluation of the astronomical time scale for the Paleocene and earliest Eocene. Earth and Planetary Science Letters, 300:139-151.

Hull, P.M., Norris, R.D., Bralower, T.J., and Schueth, J.D. 2011. A role for chance in marine recovery from the end-Cretaceous extinction. Nature Geoscience, 4:856-860.

Ingram, B.L. 1995. High-resolution dating of deep-sea clays using $\mathrm{Sr}$ isotopes in fossil fish teeth. Earth and Planetary Science Letters, 134(3):545-555.

Iverson, R.L. 1990. Control of Marine Fish Production. Limnology and Oceanography, 35:1593-1604.

Jackson, J.B.C., Kirby, M.X., Berger, W.H., Bjorndal, K.A., Botsford, L.W., Bourque, B.J., Bradbury, R.H., Cooke, R., Erlandson, J., Estes, J.A., Hughes, T.P., Kidwell, S., Lange, C.B., Lenihan, H.S., Pandolfi, J.M., Peterson, C.H., Steneck, R.S., Tegner, M.J., and Warner, R.R. 2001. Historical overfishing and the recent collapse of coastal ecosystems. Science, 293(5530):629-638.

Johns, M. 1993. Taxonomy and biostratigraphy of Middle and Upper Triassic ichthyoliths from northeastern 
British Columbia. Unpublished Masters Thesis, University of Victoria, Victoria, BC, Canada.

Johns, M.J., Barnes, C.R., and Narayan, Y.R. 2005. Cenozoic and Cretaceous ichthyoliths from the Tofino Basin and western Vancouver Island, British Columbia, Canada. Palaeontologia Electronica, 8.2.29A: 1-202 http://palaeo-electronica.org/paleo/ 2005 2/icht/issue2_05.htm

Johns, M.J., Barnes, C.R., and Narayan, Y.R. 2006. Cenozoic ichthyolith biostratigraphy; Tofino Basin, British Columbia. Canadian Journal of Earth Sciences/ Revue Canadienne des Sciences de la Terre, 43(2):177-204.

Kelly, D.C., Bralower, T.J., and Zachos, J.C. 1998. Evolutionary consequences of the latest Paleocene thermal maximum for tropical planktonic foraminifera. Palaeogeography, Palaeoclimatology, Palaeoecology, 141(1):139-161.

Leiggi, P. and May, P. 2005. Vertebrate Paleontological Techniques (volume 1). Cambridge University Press, Cambridge.

Maisey, J. 1984. Higher elasmobranch phylogeny and biostratigraphy. Zoological Journal of the Linnean Society, 82:33-54.

Martin, E. and Haley, B. 2000. Fossil fish teeth as proxies for seawater $\mathrm{Sr}$ and $\mathrm{Nd}$ isotopes. Geochimica et Cosmochimica Acta, 64:835-847.

Moloney, C.L. and Field, J.G. 1991. The size-based dynamics of plankton food webs. I. A simulation model of carbon and nitrogen flows. Journal of Plankton Research, 13:1003-1038.

Moloney, C.L., Field, J.G., and Lucas, M.I. 1991. The size-based dynamics of plankton food webs. II. Simulations of three contrasting southern Benguela food webs. Journal of Plankton Research, 13:1039-1092.

Near, T.J., Dornburg, A., Eytan, R.I., Keck, B.P., Smith, W.L., Kuhn, K.L., Moore, J.A., Price, S.A., Burbrink, F.T., Friedman, M., and Wainwright, P.C. 2013. Phylogeny and tempo of diversification in the superradiation of spiny-rayed fishes. Proceedings of the National Academy of Sciences, 110:12738-12743.

Near, T.J., Eytan, R.I., Dornburg, A., Kuhn, K.L., Moore, J.A., Davis, M.P., Wainwright, P.C., Friedman, M., and Smith, W.L. 2012. Resolution of ray-finned fish phylogeny and timing of diversification. Proceedings of the National Academy of Sciences, 109:1369813703.

Nelson, J.S. 2006. Fishes of the World. Wiley, New York.

Powell, J. 2003. The fish bone assemblage from the Cave of Cyclope, Youra: evidence for continuity and change. British School at Athens Studies, 10:173179.

Rainsford, C., O'Connor, T., and Miracle, P. 2014. Fishing in the Adriatic at the Mesolithic-Neolithic transition: Evidence from Vela Spila, Croatia. Environmental Archaeology, 19(3):311-320.

Randall, J.E. 1961. Overgrazing of algae by herbivorous marine fishes. Ecology, 42:812.

Scher, H.D. and Martin, E.E. 2004. Circulation in the Southern Ocean during the Paleogene inferred from neodymium isotopes. Earth and Planetary Science Letters, 228:391-405.

Sibert, E., Norris, R., Cuevas, J., and Graves, L. 2016. Eighty-five million years of Pacific Ocean gyre ecosystem structure: long-term stability marked by punctuated change. Proceedings of the Royal Society of London B: Biological Sciences, 283(1831). doi:10.1098/rspb.2016.0189

Sibert, E.C., Hull, P.M., and Norris, R.D. 2014. Resilience of Pacific pelagic fish across the Cretaceous/ Palaeogene mass extinction. Nature Geoscience, 7:667-670.

Sibert, E.C. and Norris, R.D. 2015. New Age of Fishes initiated by the Cretaceous-Paleogene mass extinction. Proceedings of the National Academy of Sciences, 112:8537-8542.

Smit, J. 1982. Extinction and evolution of planktonic foraminifera after a major impact at the Cretaceous/Tertiary boundary. Geological Society of America Special Papers, 190:329-352.

Song, J. and Parenti, L.R. 1995. Clearing and staining whole fish specimens for simultaneous demonstration of bone, cartilage, and nerves. Copeia, 1:114118.

Sprules, W.G., and Munawar, M. 1986. Plankton Size Spectra in Relation to Ecosystem Productivity, Size, and Perturbation. Canadian Journal of Fisheries and Aquatic Sciences, 43(9):1789-1794.

Taylor, W.R. 1967. An enzyme method of clearing and staining small vertebrates. Proceedings of the U.S. National Museum, 122(3596):1-17.

Turner, S. 2004. Early vertebrates: analysis from microfossil evidence, p. 67-94. In Arratia, G., Wilson, M.V.H., and Cloutier, R. (eds.), Recent Advances in the Origin and Early Radiation of Vertebrates, 65. Verlag Dr. Friedrich Pfeil, Munich.

Westerhold, T., Roehl, U., Raffi, I., Fornaciari, E., Monechi, S., Reale, V., Bowles, J., and Evans, H.F. 2008. Astronomical calibration of the Paleocene time. Palaeogeography, Palaeoclimatology, Palaeoecology, 257(4):377-403. 